\title{
The relationship between fact and source memory: Findings from amnesic patients and normal subjects
}

\author{
ARTHUR P. SHIMAMURA \\ University of California, Berkeley, California \\ and \\ LARRY R. SQUIRE \\ Veterans Affairs Medical Center, San Diego, California \\ and University of California, San Diego, La Jolla, California
}

\begin{abstract}
Amnesic patients and normal subjects were presented 20 obscure facts to learn, and, after a 2-h delay, were given tests of fact recall, fact recognition, and source recall. The subjects were also given a recognition memory test in which they were asked about the learning session itself (event memory test). The amnesic patients exhibited marked impairment on all tests. Impaired source recall (i.e., source amnesia) appeared to be unrelated to impaired fact or event memory. That is, patients who made source errors remembered the facts and the learning session as well as did patients who did not make source errors. In a second experiment, normal subjects were tested 1, 3,6, and 8 weeks after learning. Source recall dropped sharply after a 6- or 8-week retention interval, demonstrating that source amnesia can occur in normal subjects when they are tested long after learning. For the normal subjects, fact and source memory were correlated. Thus, in normal subjects, source amnesia can reflect the loss of fact memory, event memory, and associations between them. However, in amnesic patients, source memory impairment was unrelated to the severity of impaired fact or event memory. Source memory impairment may reflect a specific deficit in the association of facts with their contexts.
\end{abstract}

In everyday experience, one often remembers some factual information (e.g., an experimental finding, a news item) but forgets when and where one has encountered it. Such instances represent a loss of source or contextual memory. Various theoretical accounts of memory have distinguished between memory for facts and memory for context (Hirst, 1982; Humphreys, Bain, \& Pike, 1989; Jacoby \& Dallas, 1981; Schacter, 1987; Tulving, $1972,1983)$. A common feature of these accounts is that factual (semantic) and context-specific (episodic) memory are proposed to be distinct and dissociable components of memory function (for discussion, see Mayes, Meudell, \& Pickering, 1985; McKoon, Ratcliff, \& Dell, 1986; Shimamura, 1990; Shimamura \& Squire, 1987; Squire, 1987; Tulving, 1986).

The relationship between factual and contextual memory has also been considered in neuropsychological studies

\footnotetext{
This research was supported by the Medical Research Service of the Veterans Administration, NIMH Grant MH24600, the Office of Naval Research, the McKnight Foundation, and a Bioscience Grant for International Joint Research from the NEDO, Japan. We thank Kim RiveroFrink, Loni Shutler, and Joyce Zouzounis for their assistance in testing subjects, and Gus Craik, Frank Haist, Gail Musen, and Stuart Zola-Morgan for helpful comments on earlier drafts. Requests for reprints should be sent to L. R. Squire, Department of Psychiatry (V116-A), Veterans Affairs Medical Center, 3350 La Jolla Village Dr., San Diego, CA 92161.
}

of memory-impaired patients. Indeed, it has been argued that amnesic patients exhibit a specific impairment of contextual (Hirst, 1982; Huppert \& Piercy, 1976; for review, see Mayes et al., 1985) or episodic memory (Cermak, 1984; Kinsbourne \& Wood, 1975; for review, see Schacter $\&$ Tulving, 1982). Yet despite these proposals, a number of findings suggest that this kind of distinction cannot account for the pattern of impairment observed in amnesic patients (Gabrieli, Cohen, \& Corkin, 1988; Ostergaard, 1987; Shimamura \& Squire, 1987). Thus, in addition to their difficulty in learning item and event information encountered after the onset of amnesia, amnesic patients are also impaired in their ability to acquire new factual information (Gabrieli et al., 1988; Shimamura \& Squire, 1987). Moreover, on tests of premorbid memory, both factual and contextual (i.e., autobiographical) memory are impaired (Albert, Butters, \& Levin, 1979; Baddeley \& Wilson, 1986; Butters \& Cermak, 1986; MacKinnon \& Squire, 1989; Shimamura \& Squire, 1987; Squire, Haist, \& Shimamura, 1989). Thus, it is difficult to argue that amnesia produces only an impairment of contextual or episodic memory (for review, see Mayes et al., 1985; Shimamura, 1989).

There is evidence, however, that in some amnesic patients contextual memory is disproportionately impaired relative to factual memory. For example, memory for temporal order information is disproportionately affected 
in patients with Korsakoff's syndrome but not in other amnesic patients (Huppert \& Piercy, 1976; Meudell, Mayes, Ostergaard, \& Pickering, 1985; Shimamura, Janowsky, \& Squire, 1990; Squire, 1982; Squire, Nadel, $\&$ Slater, 1981). The severity of impairment in temporal order memory can differ between two groups of amnesic patients despite the fact that the two groups are equivalently impaired in recall and recognition memory of facts or items (Shimamura et al., 1990; Squire, 1982). Moreover, amnesic patients can exhibit a greater impairment in temporal order memory than control subjects do, even when the control subjects are tested after a long retention interval in order to match their fact or item memory scores to those of the amnesic patients (Meudell et al., 1985).

Disproportionate deficits in temporal order memory appear to be related to frontal lobe pathology. First, impaired temporal order memory was observed in patients with frontal lobe lesions, even though fact and event memory were preserved (Milner, 1971; Shimamura et al., 1990). Second, impaired temporal order memory in patients with Korsakoff's syndrome was correlated with impairment on neuropsychological tests sensitive to frontal lobe damage (Squire, 1982). Third, recent quantitative analysis of computed tomography (CT) scans in patients with Korsakoff's syndrome revealed frontal lobe atrophy in addition to midline diencephalic damage (Shimamura, Jernigan, \& Squire, 1988; see also Jacobson \& Lishman, 1987; Kopelman, 1989).

Another example of a contextual or episodic memory impairment that seems to occur out of proportion to impaired factual memory is the phenomenon of source amnesia. Some amnesic patients, after successfully recalling recently presented facts, fail to identify the learning session as the source of the facts (Schacter, Harbluk, \& McLachlan, 1984; Shimamura \& Squire, 1987). Source memory impairment is also prominent in older adults, which suggests that aging affects contextual memory more than fact memory (Janowsky, Shimamura, \& Squire, 1989; McIntyre \& Craik, 1987).

Interestingly, patients who exhibit source amnesia for facts and those who do not can be equivalently impaired on recall and recognition tests for the facts themselves (Shimamura \& Squire, 1987). Also, control subjects tested at a longer (1-week) retention interval in order to match their recall and recognition memory for facts to that of the amnesic patients do not exhibit source amnesia (Schacter et al., 1984; Shimamura \& Squire, 1987). Finally, patients with frontal lobe lesions can exhibit source memory impairment despite intact fact memory (Janowsky, Shimamura, \& Squire, 1989). Thus, source memory impairment appears to be a loss of contextual or episodic memory that can occur in amnesic patients independently of impaired factual memory, possibly as a result of frontal lobe dysfunction.

These findings suggest that source memory is a dissociable component of memory function much like temporal order memory. However, several additional questions about source amnesia remain. First, how can an amnesic patient remember a fact that was presented during a learning session but not remember the session itself? One possibility is that the source itself has actually been forgotten; alternatively, the association between acquired information and the learning event may have been lost. One way to address this issue is to determine directly how well amnesic patients who commit source errors actually remember the learning event (e.g., recognizing aspects of the study session: the kind of material, the format of presentation, the type of response). Second, what structures and functions must be damaged to produce source amnesia? Can frontal lobe dysfunction explain which patients exhibit source errors and which do not? Third, what is the relationship between source memory and fact memory in normal subjects? Normal subjects tend not to exhibit source errors when the retention interval is 1 week or less (Schacter et al., 1984; Shimamura \& Squire, 1987). Do they exhibit source errors at longer intervals? If so, are fact memory and source memory correlated, or are they unrelated?

In two experiments, we assessed the relationship between fact memory and source memory. In Experiment 1, amnesic patients and control subjects were presented facts to learn (e.g., "The official flower of British Columbia is the dogwood"), and after a 2 -h retention interval they were asked to recall both the facts and the last time that they had encountered the facts (i.e., source recall). In addition, subjects took a recognition memory test for the facts as well as a recognition memory test for the learning event (e.g., "Was the material presented on sheets of paper or index cards?'). In Experiment 2, we evaluated forgetting of fact memory, source memory, and event memory in normal subjects across an 8-week period. Subjects were given the same study-test procedure that was used in Experiment 1, except that the retention interval was $1,3,6$, or 8 weeks. In this way, we determined the relationship between fact and source memory at several points during forgetting.

\section{EXPERIMENT 1}

\section{Method}

\section{Subjects}

Amnesic patients. We tested 12 amnesic patients: 7 patients with alcoholic Korsakoff's syndrome, 3 with amnesia due to an episode of anoxia or ischemia, 1 with amnesia due to a bilateral thalamic infarction, and 1 with amnesia of uncertain etiology. The patients with Korsakoff's syndrome ( 5 men and 2 women) have been studied as a group for 3 years (Janowsky, Shimamura, Kritchevsky, \& Squire, 1989; Squire \& Frambach, 1990; Squire et al, , 1989). The memory impairment for 6 of these 7 (all but R.C.) has been documented previously (Squire \& Shimamura, 1986). Of the 5 other patients, A.B. became amnesic in 1976 following an anoxic episode during cardiac arrest; G.D. became amnesic in 1983 following a period of hypotension that occurred during major surgery; L.M. became amnesic in 1984 as the result of a respiratory arrest that occurred during an epileptic seizure; M.G. became amnesic 
in 1986 following a bilateral thalamic infarction that was confirmed by magnetic resonance (MR); and W.H. became amnesic in 1986, but without a known precipitating event. His amnesia appeared within a period of a few days at the most, without known head trauma, seizure, or unconsciousness. MR scans revealed bilateral hippocampal pathology (Press, Amaral, \& Squire, 1989). The five non-Korsakoff amnesic patients have also been studied as a group for several years (Janowsky, Shimamura, et al., 1989; Shimamura \& Squire, 1988; Squire et al., 1989).

Because we were concerned with the overall performance of amnesic patients, all 12 patients are considered here as a single group (individual scores are presented in the Results section). The 12 amnesic patients averaged 56.9 years of age and 12.7 years of education. They had an average Wechsler Adult Intelligence Scale-Revised IQ (WAIS-R) score of 102.2. On the Wechsler Memory ScaleRevised (WMS-R), they scored 96.8 on Attention and Concentration, 73.6 on Verbal Memory, 77.7 on Visual Memory, 69.0 on General Memory, and 56.0 on Delayed Memory. The WAIS-R and WMS-R are standardized with a mean of 100 and standard deviation of 15 . Thus, for the amnesic patients, the average WAIS-R score and the average Attention and Concentration index scores were within the normal range. However, every patient scored at least 2 standard deviations below average on the Delayed Memory index. Individual scores on the WAIS-R and WMS-R for these 12 patients are presented in Squire et al. (1989).

Free recall of a short prose passage ( 21 total segments) was 5.4 segments for immediate recall and 0 segments for delayed (12 min) recall. Copy and delayed (12 $\mathrm{min}$ ) recall of a complex diagram (ReyOsterrieth figure, Lezak, 1983) averaged 27.4 and 3.7 segments, respectively (36 segments total). Paired-associate memory for 10 unrelated noun pairs on each of three successive trials was $0.7,0.5$, and 1.8. Also, on five successive study-test learning trials (Rey Auditory Verbal Learning Test; Lezak, 1983) these patients averaged 3.7, 5.0, 5.3, 5.3, and 5.3 for free recall; and they averaged $21.8,24.5,24.825 .6$, and 26.8 correct for yes/no recognition of 15 old words and 15 new words.

Neuropsychological screening and independent neurological examination indicated that memory impairment was the only remarkable deficit of higher cortical function. The amnesic patients averaged 132.0 points out of a possible 144 points on the Dementia Rating Scale (Mattis, 1976), losing most of their points on the memory subportion of the test. Additional neuropsychological data for these patients, as well as data for control subjects on the justmentioned tests, can be found in Janowsky, Shimamura, et al. (1989) and Squire and Shimamura (1986).

Control subjects. Eight volunteers or employees at the VA Medical Center ( 4 men and 4 women) served as control subjects for the 12 amnesic patients. They averaged 53.9 years of age and had an average education level of 13.9 years. They were matched to the 12 amnesic study patients on the basis of two WAIS-R subtest scores, Information ( $M=21.8 ; M=19.7$ for the amnesic patients) and Vocabulary ( $M=53.8 ; M=52.7$ for the amnesic patients). Immediate and delayed (12 $\mathrm{min})$ recall of a short prose passage averaged 8.8 and 7.4 , respectively.

\section{Materials}

A set of 30 obscure facts were compiled from trivia and reference books (e.g., "The name of the dog on the Cracker Jacks box is Bingo"). The facts were different from those used in previous studies of fact and source memory (Janowsky, Shimamura, \& Squire, 1989; Shimamura \& Squire, 1987), but they were similar in difficulty. The facts were divided into three sets of 10 facts each. Two of the three sets were presented during both the study and the test sessions. The third set was presented only during the test session in order to assess fact and source memory for information learned outside the study session. The three sets were rotated across the study and test sessions so that every 3 subjects formed a completely counterbalanced group.

In addition to these questions, a pool of 20 extra.questions was compiled, and these were used as substitutes for the study questions that could be answered correctly prior to the study session (see below). Also, two sets of 10 easy questions were included (e.g., "What is the tool used to pound nails?"); one set was presented during the study session, and the other set was presented during the test session. The easy questions at study were used to make the study session appear less difficult and were not evaluated during the test session. The easy questions at test assured that there would be several questions recalled for which the source of the information was not the study session itself. Across subjects, each set of easy questions was used equally often in the study and test sessions.

\section{Procedure}

The procedure was similar to the one used by Shimamura and Squire (1987, Experiment 1), except for the addition of an event recognition test (see below). The subjects were first told that they would be asked to learn some general-information facts. In order to identify facts that were not known to the subjects prior to the study session, each fact was first presented on a card in the form of a question (e.g., "What is the name of the dog on the Cracker Jacks box?"'), and the subjects were asked to recall the fact. During this "screening" phase of the study session, the 10 easy questions were mixed together with the difficult questions, simply to make the session less challenging. If the subject answered one of the difficult questions correctly, that question was discarded and another was substituted in its place. If the subject was unable to answer a question, the answer was provided by the experimenter in the form of a written statement (e.g., "The name of the dog on the Cracker Jacks box is Bingo" '), and the subject was asked to read the answer and remember it. The study session continued in this fashion until the subject had been given 20 facts that could not be recalled. Following this first learning trial, the same 20 nonrecalled facts were presented a second time as written statements, and the subjects were again asked to read and remember each statement.

After a 2-h interval, fact recall, fact recognition, source recall, and recognition memory for the learning event were tested. During the retention interval, subjects were released and scheduled for more testing after the 2 -h interval. First, fact and source recall were tested. During the fact and source recall tests, no reference was made to the previous study session. Instead, subjects were simply asked to answer some general-information questions. Whenever they answered a question correctly, they were also asked to report where they had learned the information ("That's correct. Can you tell me where you learned the answer?"). In addition, subjects were asked, "When was the most recent time you heard that information?" Thus, even if a subject thought that a fact presented during the study session had also been encountered at some earlier time, the subject was always asked to identify the most recent source for that information. In this way, fact and source recall were assessed for the 20 difficult facts that had been learned during the study session, for 10 new difficult facts, and for 10 new easy facts. Source recall performance for correctly recalled study facts was based on the percentage of times a subject correctly identified the prior ștudy session as the most recent source of the information.

Following the fact and source recall tests, subjects were given a 10 -item, recognition memory test for the learning event itself. The event recognition test consisted of one yes/no question and nine two-choice questions about the study session that had occurred $2 \mathrm{~h}$ earlier (e.g., " Did I ask you to study some information?", " Actually, I presented you some information about two hours ago. Can you tell me if the information that I presented to you was printed on sheets of paper or on index cards?"; "Actually, you saw index cards. Were the cards colored or white?"; "The cards were colored. 
Were the cards pink or yellow?"; "On each card, was there only one word or was there a sentence?"; "Was the information printed in capital or lowercase letters?"). Each question built on the answer to the previous one, which was always provided by the experimenter. Following this 10 -item event recognition test, an 8 alternative, forced-choice recognition test was administered for all 40 facts ( 20 old facts, 10 new difficult facts, and 10 new easy facts). The distractors were constructed to match the test questions (e.g., "What is the name of the dog on the Cracker Jacks box?', answer: "Bingo"'; distractors: "Milo," “Buttons," "Pal," "Spot," "Penny," "Fido," “Manfred”). Fact recognition performance was based on the number of old facts recognized correctly (based on a total of 20 fact questions).

\section{Results and Discussion}

Figure 1 (upper panel) shows fact-learning performance of amnesic patients and control subjects on tests of cued recall and recognition memory for 20 facts that could not be recalled prior to the study session. Amnesic patients exhibited markedly impaired performance on both recall and recognition memory tests $[t \mathrm{~s}(18)>4.7, p<.01]$. On the recall test, amnesic patients averaged $32.9 \%$ correct and control subjects averaged $91.9 \%$ correct (baseline $=$ $0 \%$ correct recall). Both groups performed above baseline levels $(p s<.01)$. The difference in recall performance between groups was not attributable to differences in prior knowledge of facts, because the amnesic patients recalled about as many facts as did the control subjects during the initial screening test (amnesic patients $=3.9$ facts; control subjects $=5.5$ facts).

On the recognition test, amnesic patients averaged $67.5 \%$ correct, and control subjects averaged $98.1 \%$ correct (baseline for the two groups averaged 30.4\%). The recognition memory baseline score was based on how well subjects recognized the answers to new questions that could not be recalled. Out of 10 factual questions presented only during the test session, the baseline score was the recognition score for the questions that could not be answered in the recall test. Both groups performed above baseline levels $(p s<.01)$. Without any learning trials, one might expect above-chance recognition memory for factual questions that could not be recalled. Thus, significant recognition memory scores above baseline represent the increase in recognition memory gained from the study session itself.

Source memory was also impaired in the amnesic patients $[t(18)=2.4, p<.05$; see Figure 1]. Amnesic patients recalled the study session as the source for $58.6 \%$ of the study facts that were correctly recalled. None of the control subjects committed any source errors (i.e., source recall $=100 \%$ correct). In agreement with previous findings (Shimamura \& Squire, 1987), source memory ability was quite variable across amnesic patients (see the individual scores in Table 1; of the patients listed, the first 6 patients with Korsakoff's syndrome, as well as A.B., G.D., and L.M., were also tested in the previous study). Four amnesic patients exhibited source errors for every fact that was recalled correctly. These patients never mentioned the learning session that occurred $2 \mathrm{~h}$ prior to the test session. Instead, they typically stated that the fact
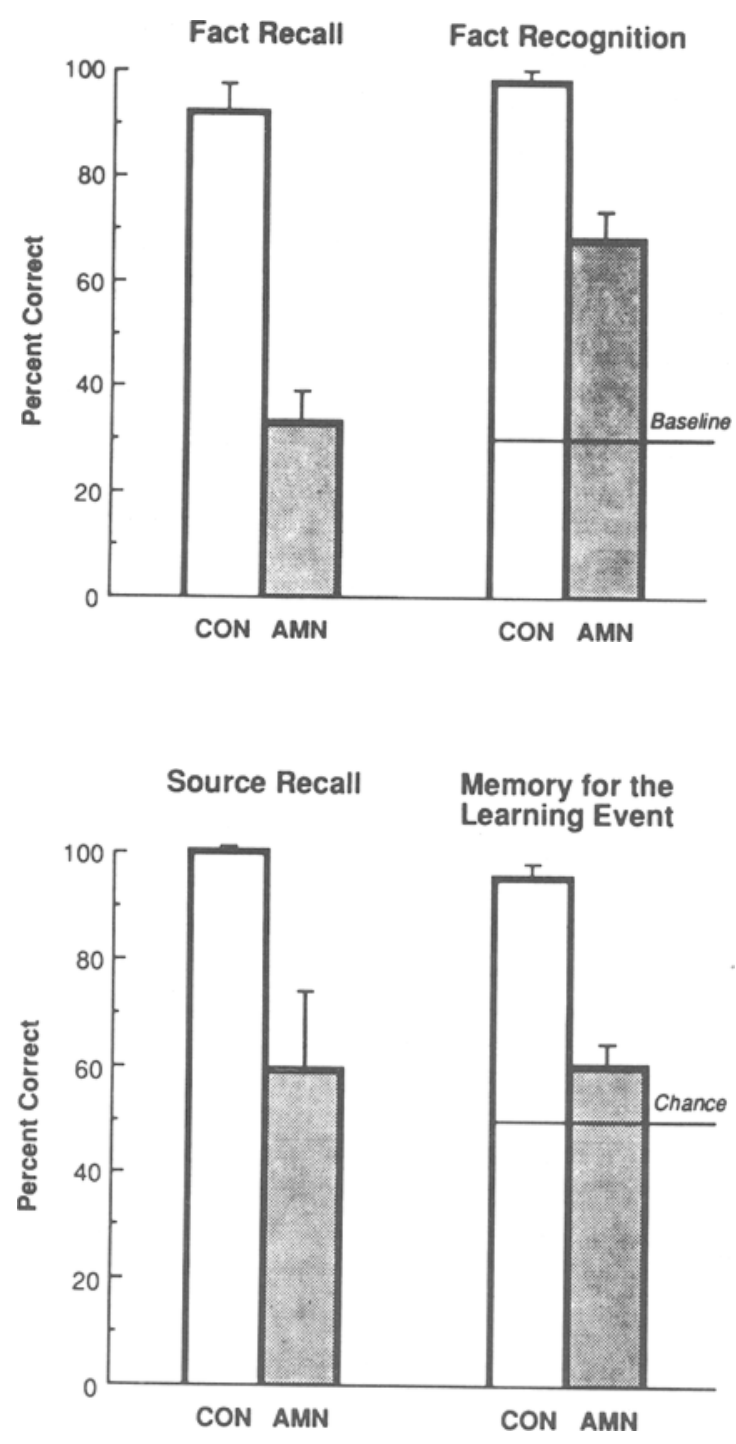

Figure 1. Top panel shows fact recall and fact recognition performance by control subjects (CON, $n=8$ ) and amnesic patients (AMN, $n=12$ ) tested $2 \mathrm{~h}$ after a learning session. The baseline for fact recognition indicates the level of performance that could be achieved without the benefit of the learning session. Bottom panel shows source recall and memory for the learning event (event recognition test). The event recognition test was two-alternative, forced-choice (chance $=50 \%$ ). Error bars indicate standard errors of the mean.

was learned from a newspaper, a movie, a television show, or simply "long ago." Five other amnesic patients never committed source errors. It should be noted that source errors for nonpresented facts (i.e., identifying the study session as the source for any of the 10 easy or 10 difficult facts that were asked about only in the test session) were low for both amnesic and control groups (9.4\% errors for amnesic patients, $0 \%$ errors for controls). In particular, the 5 patients with perfect source recall for the questions presented during study answered correctly an average of 2.0 difficult new facts but never made source errors for these facts. Thus, good source recall could not 
Table 1

Fact Recall, Fact Recognition, Source Recall, and Event Recognition Performance (in Percent) of Amnesic Patients and Control Subjects

\begin{tabular}{lccrc}
\hline \multicolumn{1}{c}{ Subject(s) } & $\begin{array}{c}\text { Fact } \\
\text { Recall }\end{array}$ & $\begin{array}{c}\text { Fact } \\
\text { Recognition }\end{array}$ & $\begin{array}{r}\text { Source } \\
\text { Recall }\end{array}$ & $\begin{array}{c}\text { Event } \\
\text { Recognition }\end{array}$ \\
\hline KOR N.C. & 15 & 45 & 100 & 80 \\
KOR V.F. & 50 & 80 & 90 & 40 \\
KOR B.L. & 40 & 80 & 88 & 70 \\
KOR D.M. & 45 & 45 & 0 & 60 \\
KOR P.N. & 20 & 80 & 100 & 60 \\
KOR J.W. & 15 & 45 & 0 & 80 \\
KOR R.C. & 20 & 60 & 25 & 50 \\
A.B. & 45 & 85 & 100 & 50 \\
G.D. & 20 & 55 & 100 & 40 \\
M.G. & 60 & 85 & 0 & 50 \\
W.H. & 15 & 60 & 0 & 60 \\
L.M. & 50 & 90 & 100 & 80 \\
$M(n=12)$ & 32.9 & 67.5 & 58.6 & 60.0 \\
Controls & & & & \\
2 h $(n=8)$ & 91.9 & 98.1 & 100.0 & 95.0 \\
1 week $(n=8)$ & 65.6 & 83.1 & 93.2 & 78.8 \\
3 weeks $(n=10)$ & 40.0 & 70.0 & 89.0 & 60.0 \\
6 weeks $(n=8)$ & 31.2 & 63.1 & 54.5 & 63.8 \\
8 weeks $(n=8)$ & 42.5 & 64.4 & 56.2 & 52.5 \\
\hline
\end{tabular}

Note-KOR $=$ Korsakoff's syndrome.

be attributed to a simple response bias (e.g., always stating that any recalled fact was presented during the study session). Similarly, poor source recall could not be attributed to confused or random responding.

Source recall did not appear to be related to the level of fact memory ability exhibited by the patients. The 6 patients with the best source recall performance (source recall $=98.3 \%)$ recalled about as many facts $(33.3 \%)$ as did the 6 patients with the worst source recall performance (source recall $=18.8 \%$; fact recall $=32.5 \%$ ). Also, the 6 amnesic patients with the best source memory scored $72.5 \%$ on the fact recognition test, whereas the 6 patients with the worst source memory scored $62.5 \%$. The group of 6 patients with the worst source recall scores included 1 patient with a rather good performance score $(88 \%$ correct source recall). However, the findings just presented do not change when this patient is instead assigned to the group with good source memory ability (see Table 1).

Amnesic patients exhibited impaired performance on the event recognition memory test [see Figure $1 ; t(18)=6.2$, $p<.01]$. This test, in which incidental event memory was tested, consisted of 10 forced-choice recognition questions about the learning session. The score obtained by the amnesic patients (60\% correct) was significantly above the chance level of $50 \%[t(11)=2.34, p<.05]$. Because the average score was nevertheless only $60 \%$, we also calculated the score for each patient on the basis of the first five (easier) questions of the 10-event memory questions. The 12 patients listed in Table 1 obtained scores as follows: $100 \%, 20 \%, 80 \%, 80 \%, 80 \%, 80 \%, 60 \%, 60 \%$, $60 \%, 80 \%, 60 \%, 100 \%(M=72 \%)$. Clearly, most of the patients were capabie of some degree of event memory.

Interestingly, performance on this test was not related to source memory ability in the amnesic patients. The 6 amnesic patients with the best source recall ability performed slightly poorer on the event recognition test (event memory $=58.3 \%$ ) than did the 6 patients with the worst source recall ability (event memory $=61.7 \%$ ). When only the first five questions were used for this comparison, the corresponding values were $73.3 \%$ and $70.0 \%$.

\section{EXPERIMENT 2}

Experiment 1 showed that source memory impairment in amnesic patients was not related to the level of fact recall nor to the level of event memory. We next asked whether these same findings would be obtained for normal subjects when memory performance was weakened by increasing the retention interval. Accordingly, in Experiment 2, we tested different groups of normal subjects at several long retention intervals $(1,3,6$, and 8 weeks), and we assessed fact memory, source memory, and event memory at each interval. Both the study and the test sessions were identical to those used in Experiment 1.

\section{Method}

\section{Subjects}

A total of 34 healthy normal subjects (volunteers or employees at the VA Medical Center) were tested. The subjects were assigned to four groups, each tested at different retention intervals. Eight subjects were tested after 1 week, 10 were tested after 3 weeks, 8 were tested after 6 weeks, and 8 were tested after 8 weeks. The 34 subjects averaged 56.2 years of age and had an average education level of 14.9 years. They were matched to the 12 amnesic study patients tested in Experiment 1 on the basis of two WAIS-R subtest scores, Information $(M=21.6 ; M=19.7$ for the amnesic patients) and Vocabulary ( $M=54.0 ; M=52.7$ for the amnesic patients). Many of these individuals had participated as control subjects in other studies in our laboratory. Because participation in other experimental sessions with the same experimenters might be expected to influence source memory judgments, we equated the four groups on the basis of the average number of sessions in other experiments that the subjects had previously experienced (average number of prior test sessions during the past 2 years $=7.6$ ).

\section{Procedure}

The procedure was identical to that used in Experiment 1. Briefly, the subjects learned the answers to 20 factual questions that they could not answer in a screening test. Fact recall, fact recognition, source recall, and event recognition memory were tested after four different retention intervals $(1,3,6$, and 8 weeks). Source recall was assessed by asking subjects to recall "the last time you heard the information" for every fact that was correctly recalled. Event memory was assessed by a 10 -item, forced-choice recognition test about the study session.

\section{Results and Discussion}

Figure 2 (upper panel) shows the forgetting curve for fact recall across the four retention intervals. The figure includes the scores obtained by control subjects and amnesic patients in Experiment 1 (2-h retention interval). A one-way analysis of variance showed that fact recall performance declined significantly across delays [ $1-8$ weeks; $F(3,30)=7.9, p<.01]$. Post hoc comparisons showed that performance after 1 week was better than perfor- 

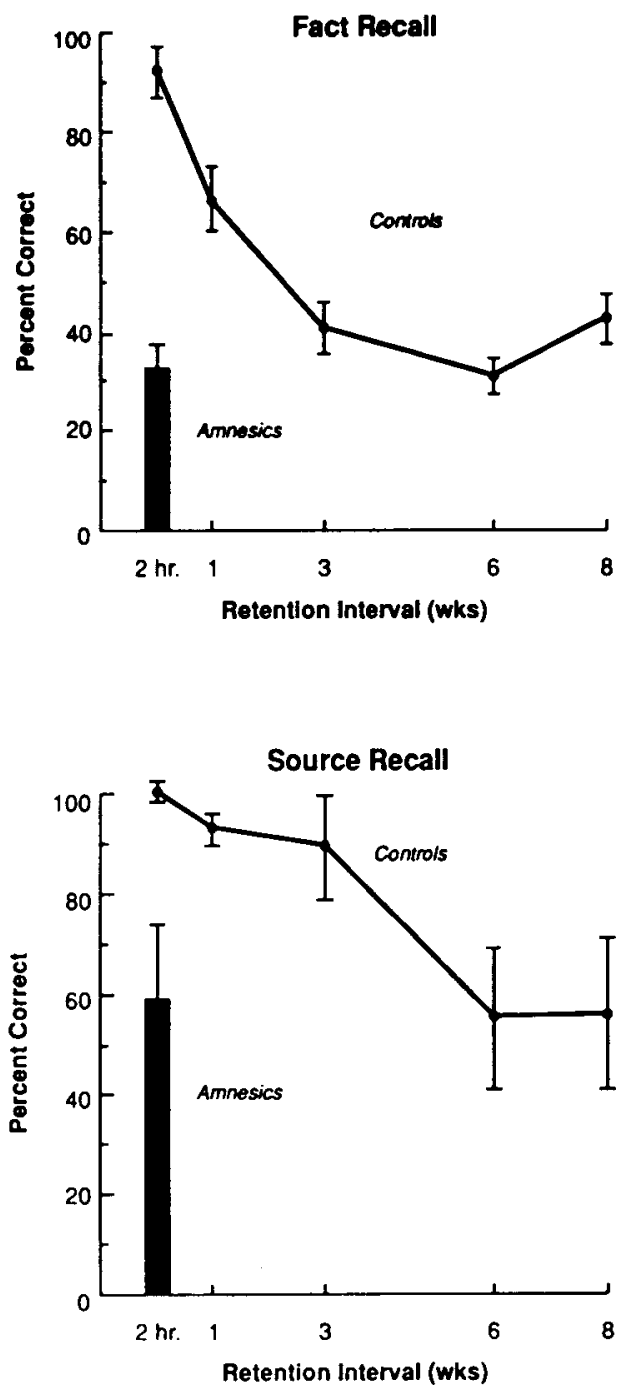

Figure 2. Top panel shows fact recall performance of five groups of control subjects tested at different retention intervals. Also shown are the results for amnesic patients tested after a $2-h$ retention interval (black bar, taken from Figure 1). Bottom panel shows source recall performance of the same control subjects and amnesic patients. The source recall score was the percentage of times that subjects identified the recent learning session as the source for a study fact that was correctly recalled (i.e., percent correct source recall contingent upon correct fact recall). Error bars indicate standard errors of the mean.

mance after 3,6 , or 8 weeks ( $t \mathrm{~s}>2.3, p<.05$ ), but performance after 3,6 , or 8 weeks was similar (all pairwise comparisons, $p \mathrm{~s}>.10$ ).

The pattern of performance on the fact recognition and event recognition tests was similar to the pattern observed on the fact recall test (see Table 1). Specifically, fact recognition performance declined with delays $[F(3,30)=7.9$, $p<.01]$, and performance after a 1-week delay was significantly better than performance after a 3-, a 6-, or an 8 -week delay $(t \mathrm{~s}>2.2, p \mathrm{~s}<.05$ ). There were no significant differences between groups tested with delays of
3 weeks or longer. For the event recognition test, there was also a significant effect of delay $[F(3,30)=4.7$, $p<.01]$. The 1-week group remembered the learning session significantly better than did the 3-, 6-, or 8-week groups ( $t \mathrm{~s}>2.3, p \mathrm{~s}<.05$ ), and the 3-, 6-, and 8-week groups performed similarly. This test of incidental event memory was particularly difficult after long retention intervals. Indeed, performance after an 8-week delay was only $52.5 \%$ correct and was not significantly above the $50 \%$ chance level.

Source recall declined significantly with increasing delay $[F(3,30)=3.3, p<.01]$, but the pattern of forgetting was quite different from the pattern observed for fact recall, fact recognition, and event recognition (Figure 2, bottom panel). For example, although fact recall performance declined sharply between $2 \mathrm{~h}$ and 3 weeks after learning (from $91.9 \%$ to $40 \%$ ), source recall was quite good during that period (above 89\%). Indeed, even at 3 weeks after learning, 8 of the 10 subjects performed at $100 \%$ correct. Yet during the period that fact recall was relatively stable (between 3 and 8 weeks after learning), source recall performance declined sharply from $89 \%$ to $55 \%$. This difference in forgetting curves was statistically significant, as is indicated by a test (fact recall vs. source recall) $\times$ delay interaction $[F(3,30)=3.5, p=.027]$.

Figure 3 illustrates the same point in a different way. The shaded area in Figure 3 shows the proportion of source errors committed when fact memory was tested at each of the 5 retention intervals. Thus, source errors were negligible during the first 3 weeks after learning, but they occurred for nearly half of the correctly recalled facts when memory was tested after a 6- or an 8-week interval. Thus, in normal forgetting, source information was lost as the retention interval increased, even when memory for facts remained rather stable.

As in Experiment 1, subjects rarely committed source errors for nonpresented facts. That is, the subjects rarely identified the study session as the source for a fact that was presented only during the test session (source errors for new facts: $1.8 \%$ for the 1-week group, $2.7 \%$ for the 3-week group, $1.0 \%$ for the 6-week group, $6.6 \%$ for the 8 -week group). Thus, the increase in source errors for study facts as a function of retention interval (i.e., failing to identify the study session as the source of a study fact) cannot be explained as a change in response bias across groups. Instead, the pattern of source recall performance shown in Figure 2 reflects true forgetting of source information.

Comparisons of the amnesic patients and the control subjects showed that fact recall performance by the amnesic patients (2-h delay) was poorer than performance by the control subjects tested after a 1-week delay $(t=4.3, p<.01)$ but not significantly different from the performance of control subjects tested after a 3-, a 6-, or an 8-week delay. On the source recall test, the amnesic patients performed more poorly than the control subjects who were tested after either a 1- or a 3-week delay $(t \mathrm{~s}=2.5, p<.05)$, but not differently from the control 


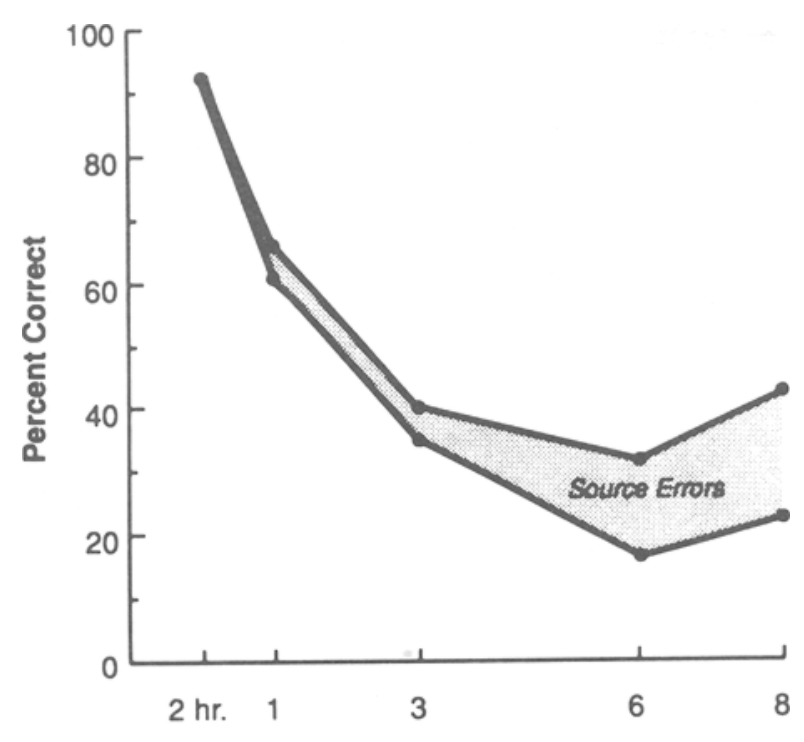

Retention Interval (wks)

Figure 3. The proportion of source errors (shaded area) made by control subjects at different retention intervals. The top curve shows the percentage of facts recalled out of 20 at each of five retention intervals. The bottom curve shows source recall performance as a percentage of the same 20 facts. Note the increase in the proportion of source errors at the 6- and 8-week intervals.

subjects tested after a 6- or an 8-week delay. Thus, source memory in amnesic patients appeared to be disproportionately impaired when the patients were compared with control subjects tested after a 3-week retention interval. Yet this disproportionate deficit was not observed when the amnesic patients were compared with control subjects tested after a 6- or an 8-week delay. Indeed, when these control subjects were compared with the amnesic patients, both fact and source memory were closely matched (see Table 1).

\section{GENERAL DISCUSSION}

Amnesic patients exhibited marked impairment on tests of fact recall, fact recognition, source recall, and event recognition (Experiment 1). Thus, there was no indication that amnesia selectively impairs source (contextual) memory while sparing factual memory (see also Gabrieli et al., 1988; Ostergaard, 1987; Shimamura \& Squire, 1987, 1988). As in a previous study (Shimamura \& Squire, 1987), source recall performance was extremely variable in amnesic patients. Five of the 12 amnesic patients were always able to report correctly that a recalled fact was recently presented to them by the experimenter, whereas 4 of the patients consistently erred and never reported the study session as the source of study facts.

The variability of performance on the source memory test across amnesic patients could not be accounted for by differences in the overall severity of their amnesia. When amnesic patients were divided into subgroups on the basis of their source recall performance, the 6 patients with the best source recall ( $98 \%$ correct) had virtually the same fact recall score (within 1\%) as did the 6 patients with the worst source recall $(18.8 \%$ correct). Moreover, these two subgroups performed similarly on the event recognition test ( $58 \%$ vs. $62 \%$ ). Because performance on the event recognition test was low overall (chance $=50 \%$ ), the failure to observe a difference between the two subgroups on this comparison may have been the result of a floor effect. Accordingly, we also analyzed the data by using only the first five (easiest) questions on the event recognition test. Despite the fact that event recognition performance was well above chance levels for these questions, these two subgroups again performed similarly on the event recognition test $(73.3 \%$ vs. $70.0 \%$ ). Together, these findings indicate that neither impaired fact memory nor impaired event memory can account for the variability in source recall exhibited by amnesic patients.

In Experiment 2, forgetting curves for fact memory, event memory, and source memory performance were analyzed in normal subjects by administering tests at 1 , 3,6 , or 8 weeks after learning. As can be seen in Table 1 , fact recall, fact recognition, and event recognition performance declined sharply between 1 and 3 weeks after learning. Performance was fairly stable 3-8 weeks after learning. By contrast, source recall performance was above $89 \%$ at 1 and 3 weeks after learning, but it declined sharply between 3 and 6 weeks (ceiling effects at the 1- and 3-week intervals may have concealed actual levels of source recall performance at these time intervals). Thus, source memory loss readily occurs in normal forgetting when retrieval is attempted after long retention intervals, a finding that corroborates everyday experience.

Analyses of the relationship between fact and source recall indicated that these two measures were significantly correlated in normal forgetting. For example, when source recall performance was not affected by ceiling effects (i.e., performance after a 6- or an 8-week retention interval), a significant Spearman rank-order correlation was obtained between source recall and fact recall performance (correlation $=.60, p<.05 ; n=16$ ). That is, in contrast to the amnesic patients (correlation $=.10 ; n=12$ ), the normal subjects who were able to recall many facts could also correctly recall the source of those facts; and the normal subjects who recalled few facts had difficulty recalling the source of those facts. Also, source recall tended to be related to event memory for the learning session itself (the rank-order correlation of .40 approached significance, $p=.07 ; n=16$ ). For amnesic patients, the correlation between source recall and event memory performance was .04. The amnesic patients did exhibit a significant correlation between fact recall and fact recognition (correlation $=.72, p<.05$ ). Thus, for normal subjects source errors reflect, at least in part, a generally declining memory for the facts, the learning event, and the association between the two (i.e., source memory). For the amnesic patients, source errors reflect a dispropor- 
tionate impairment in source memory that cannot be accounted for by generally poor memory. These findings replicate previous findings which showed that source memory in amnesic patients cannot be described as a result of generally weak memory abilities (Schacter et al., 1984; Shimamura \& Squire, 1987).

There is, however, one puzzling feature of source memory impairment. If source memory impairment in amnesia reflects to some extent a selectively affected process rather than a generally weak memory system, it should not be possible to find that both the fact and the source memory scores of amnesic patients are similar to the fact and source memory scores of delayed control subjects (tested after long delays of 6 and 8 weeks). Yet, when the amnesic patients are compared with the control subjects tested 6 and 8 weeks after learning, source amnesia seemed to be about what it should be, given the level of fact memory ability. Closer inspection of the scores, however, suggests that the two groups were not so similar. Although the means did match, the scores of the amnesic patients were markedly bimodal, whereas the scores of the (6- and 8-week-delayed) control subjects were not. For example, whereas none of the 12 amnesic patients scored between $25 \%$ and $88 \%$ correct on the source memory test, 6 of 16 delayed control subjects scored in this range (Fisher's exact test, $p=.02$ ). This difference in the shapes of the distribution for the two groups makes it difficult to evaluate the findings that the means were similar, but it does show that some of the amnesic patients exhibited severely impaired source memory performance.

Frontal lobe dysfunction may be one factor that affects source memory. Patients with frontal lobe lesions exhibit source memory impairment for previously learned facts, despite normal memory for the facts themselves (Janowsky, Shimamura, \& Squire, 1989). Interestingly, the source memory impairment in this case appears to reflect a disconnection between facts and their source rather than amnesia for the source itself. All of the patients with frontal lobe lesions were able to recall the prior learning session that occurred 1 week before the test session. Also, they sometimes committed source errors for new facts by misidentifying the learning session as the source of facts that had never been presented in the session. Finally, patients with frontal lobe dysfunction exhibit impaired memory for temporal order despite normal item memory (Shimamura et al., 1990). Thus, patients with frontal lobe lesions exhibit intact fact and event memory, but they have difficulty connecting facts to the specific spatiotemporal context in which the facts were learned.

The source memory impairment exhibited by the amnesic patients in the present study may also reflect source disconnection. Specifically, the amnesic patients who committed many source errors were as able to recognize aspects of the learning event as were the patients who did not commit source errors, and in this respect, the source errors made by amnesic patients resemble the source er- rors made by patients with frontal lobe lesions. But there are two ways in which the amnesic patients differed from frontal patients. First, the amnesic patients committed more source errors for presented facts ( $41 \%$ errors) than did the frontal patients ( $15 \%$ errors). Second, unlike the patients with frontal lobe lesions, the amnesic patients did not make many source errors for new facts $(8.2 \%$ errors for the amnesic patients vs. $20 \%$ for the frontal patients). That is, amnesic patients rarely identified the learning session as a source for a fact that had not been presented in the learning session. Amnesic patients probably make this type of source error only rarely because they-unlike patients with frontal lobe lesions-have impaired declarative memory for the learning session.

The relationship between source memory performance and performance on other neuropsychological tests was assessed. Spearman rank-order correlations were performed between source recall performance and a test of new learning ability (General Memory index of the WMS-R) and four tests sensitive to frontal lobe dysfunction (a test of temporal order memory [Word Sequencing Test, Shimamura et al., 1990], the Wisconsin Card Sorting Test, Verbal Fluency Test, and the Initiation/Perseveration subtest of the Dementia Rating Scale). None of the correlations reached statistical significance, which indicates that none of these measures were strongly associated with source memory. The two highest correlations were obtained between source memory performance and the General Memory index of the WMS-R and between source memory performance and the test of temporal order memory, both of which resulted in rank-order correlations of $.37(n=12)$. The average correlation between source memory scores and the three other tests of frontal lobe dysfunction was -.04 . Thus, no reliable relationship could be detected between source memory performance and performance on standard tests of frontal lobe dysfunction. In a previous study by Schacter et al. (1984), a significant correlation between source memory impairment and two tests of frontal lobe dysfunction was reported. Also, Craik, Morris, Morris, and Loewen (1990) reported a significant correlation between source memory forgetting and two tests of frontal lobe dysfunction in older adults. In that study, source memory forgetting was not significantly correlated with fact recall or recognition following a 1-week retention interval. In the present study, source memory was found to be significantly correlated with fact memory in normal individuals following retention intervals of 6-8 weeks.

Do the amnesic patients who exhibit disproportionately impaired source memory have frontal lobe dysfunction in addition to damage in areas critical for declarative memory? Previously, we found that patients with Korsakoff's syndrome, but not other amnesic patients, were impaired on tests sensitive to frontal lobe dysfunction (Janowsky, Shimamura, et al., 1989; Janowsky, Shimamura, Kritchevsky, \& Squire, 1989; Shimamura et al., 1990; Squire, 
1982). Moreover, these same patients with Korsakoff's syndrome exhibit frontal lobe atrophy as shown by quantitative analyses of CT scans (Shimamura et al., 1988). Yet, source memory performance cannot easily be explained by the etiology of amnesia-some patients with Korsakoff's syndrome exhibited good source memory and some non-Korsakoff patients exhibited poor source memory (see also Shimamura \& Squire, 1987).

One possibility is that source memory depends on a particular frontal lobe function (such as connecting facts to sources), which is impaired in only some patients with Korsakoff's syndrome. Viewed in this manner, the 2 nonKorsakoff patients with source memory impairment (W.H. and M.G.) may have more frontal lobe damage affecting this particular function than do the other amnesic patients who did not exhibit source memory impairment. The difficulty with this view is that there is no confirming evidence for frontal lobe damage in patients W.H. and M.G. Patient W.H. has bilateral abnormalities in the hippocampal formation, as demonstrated directly by a highresolution MR protocol (Press et al., 1989). Patient M.G. had a bilateral thalamic infarction, which was confirmed by MR. Although the possibility of frontal lobe damage cannot be confidently excluded in these two cases, the MR scans revealed no obvious signs of frontal lobe abnormalities. Accordingly, until direct structural evidence becomes available, the hypothesis must remain tentative that source memory impairment in amnesic patients depends on frontal lobe dysfunction. Indeed, it remains possible that damage in brain areas other than the frontal lobe contributes to source memory impairment.

In conclusion, the findings from this study identify both similarities and differences in the memory processes underlying fact and source (i.e., contextual) memory. In normal forgetting, source memory performance is correlated with fact and event memory performance. Thus, to a significant degree, source memory for facts and events depends on the strength of memory for the facts and events themselves. Interestingly, in normal forgetting, source memory is quite poor after long retention intervals (greater than 6 weeks). In amnesic patients, source, fact, and event memory were impaired, but source memory performance did not appear to be related to either fact or event memory performance. This finding suggests that source memory also depends very much on the association of factual information with the context in which the information was acquired and that the formation of this association is a specific component of memory functions. Some amnesic patients, as well as patients with circumscribed frontal lobe lesions, are impaired in this component of memory, an impairment that is better termed source disconnection than source amnesia.

\section{REFERENCES}

Albert, M. S., ButTers, N., \& LeVIN, J. (1979). Temporal gradients in the retrograde amnesia of patients with alcoholic Korsakoff's disease. Archives of Neurology, 36, 211-216.

BAdDeley, A. D., \& Wilson, B. (1986). Amnesia, autobiographical memory and confabulation. In D. C. Rubin (Ed.), Autobiographical memory (pp. 225-252), Cambridge, U.K.: Cambridge University Press. Butters, N., Cermak, L. S. (1986). A case study of the forgetting of autobiographical knowledge: Implications for the study of retrograde amnesia. In D. C. Rubin (Ed.), Autobiographical memory (pp. 253-289). Cambridge, MA: Cambridge University Press.

Cermak, L. S. (1984). The episodic/semantic distinction in amnesia. In L. R. Squire \& N. Butters (Eds.), The neuropsychology of memory (pp. 55-62). New York: Guilford.

Craik, F. I. M., Morris, L. W., Morris, R. G., Loewen, E. R. (1990). Relations between source amnesia and frontal lobe functioning in older adults. Psychology \& Aging, 5, 148-151.

Gabrieli, J. D., Cohen, N. J., \& Corkin, S. (1988). The impaired learning of semantic knowledge following bilateral medial temporallobe resection. Brain \& Cognition, 7, 157-177.

HIRST, W. (1982). The amnesic syndrome: Descriptions and explanations. Psychological Bulletin, 91, 435-460.

Humphreys, M. S., Bain, J. D., \& Pike, R. (1989). Different ways to cue a coherent memory system: A theory for episodic, semantic, and procedural tasks. Psychological Review, 96, 208-233.

HuPPERT, F. A., \& PIERCY, M. (1976). Recognition memory in amnesic patients: Effect of temporal context and familiarity of material. Cortex, 12, 3-20.

JACOBSON, R. R., \& Lishman, W. A. (1987). Selective memory loss and global intellectual deficits in alcoholic Korsakoff's syndrome. Psychological Medicine, 17, 649-655.

JACOBY, L. L., \& DALLAS, M. (1981). On the relationship between autobiographical memory and perceptual leaming. Joumal of Experimental Psychology: General, 110, 300-340.

Janowsky, J. S., Shimamura, A. P., Kritchevsky, M., \& SQuire, L. R. (1989). Cognitive impairment following frontal lobe damage and its relevance to human amnesia. Behavioral Neuroscience, 103, 548-560.

Janowsky, J., Shimamura, A. P., \& SQuire, L. R. (1989). Source memory impairment in patients with frontal lobe lesions. Neuropsychologia, 7, 1043-1056.

KinsbouRNE, M., \& Wood, F. (1975). Short-term memory processes and the amnesic syndrome. In D. Deutsch \& J. A. Deutsch (Eds.), Short-term memory (pp. 258-291). New York: Academic Press.

Kopelman, M. D. (1989). Remote and autobiographical memory, temporal context memory and frontal atrophy in Korsakoff and Alzheimer patients. Neuropsychologia, 72, 437-460.

LEZAK, M. D. (1983). Neuropsychological assessment (2nd ed.), New York: Oxford University Press.

MacKInNon, D., \& SQUIRE, L. R. (1989). Autobiographical memory and amnesia. Psychobiology, 17, 247-256.

Mattis, S. (1976). Dementia Rating Scale. In R. Bellack \& B. Karasu (Eds.), Geriatric Psychiatry 1 (pp. 77-121). New York: Grune \& Stratton.

Mayes, A. R., Meudell, P. R., \& Pickering, A. (1985). Is organic amnesia cued by a selective deficit in remembering contextual information? Cortex, 21, 167-202.

McIntyre, J. S., \& Craik, F. I. M. (1987). Age differences in memory for item and source information. Canadian Journal of Psychology, 41, 175-192.

McKoon, G., RatclifF, R., \& Dell, G. S. (1986). A critical evaluation of the semantic-episodic distinction. Journal of Experimental Psychology: Learning, Memory, \& Cognition, 12, 295-306.

Meudell, P. R., Mayes, A. R., Ostergaard, A., \& Pickering, A. (1985). Recency and frequency judgments in alcoholic amnesics and normal people with poor memory. Cortex, 21, 487-511.

MILNER, B. (1971). Interhemispheric differences in the localisation of psychological processes in man. British Medical Bulletin, 27, 272-277.

OSTERGAARD, A. L. (1987). Episodic semantic and procedural memory in a case of amnesia at an early age. Neuropsychologia, 25, 341-357.

Press, G. A., Amaral, D. G., \& SQuire, L. R. (1989). The neurology of memory: A high resolution magnetic resonance imaging protocol reveals reduced size of the hippocampal formation in amnesic patients. Nature, 341, 54-57. 
SCHACTER, D. L. (1987). Memory, amnesia, and frontal lobe dysfunction. Psychobiology, 15, 21-36.

Schacter, D. L., Harbluk, J. L., \& Mclachlan, D. R. (1984). Retrieval without recollection: An experimental analysis of source amnesia. Joumal of Verbal Learning \& Verbal Behavior, 23, 593-611.

SCHACTER, D. L., \& Tulving, E. (1982). Memory, amnesia, and the episodic/semantic distinction. In R. L. Isaacson \& N. E. Spear (Eds.), Expression of knowledge (pp. 33-65). New York: Plenum.

Shimamura, A. P. (1989). Disorders of memory: The cognitive science perspective. In F. Boller \& J. Grafman (Eds.), Handbook of neuropsychology (pp. 35-73). Amsterdam: Elsevier.

Shimamura, A. P. (1990). Forms of memory: Issues and directions. In J. L. McGaugh, N. M. Weinberger, \& G. Lynch (Eds.), Brain organization and memory: Cells systems and circuits (pp. 159-173). New York: Oxford University Press.

Shimamura, A. P., Janowsky, J. S., \& Squire, L. R. (1990). Memory for the temporal order of events in patients with frontal lobe lesions and amnesic patients. Neuropsychologia, 28, 803-814.

Shimamura, A. P., Jernigan, T. L., \& SQuire, L. R. (1988). Korsakoff's syndrome: Radiological (CT) findings and neuropsychological correlates. Journal of Neuroscience, 8, 4400-4410.

Shimamura, A. P., \& SQUiRe, L. R. (1987). A neuropsychological study of fact memory and source amnesia. Journal of Experimental Psychology: Learning, Memory, \& Cognition, 13, 464-473.

Shimamura, A. P., \& SQuire, L. R. (1988). Long-term memory in amnesia: Cued recall, recognition, and confidence ratings. Journal of Experimental Psychology: Learning, Memory, \& Cognition, 14, 763-770.
SQuire, L. R. (1982). Comparisons between forms of amnesia: Some deficits are unique to Korsakoff's syndrome. Joumal of Experimental Psychology: Learning, Memory, \& Cognition, 8, 560-571.

SQuire, L. R. (1987). Memory and brain. New York: Oxford University Press.

SQuire, L. R., \& Frambach, M. (1990). Cognitive skill learning in amnesia. Psychobiology, 18, 109-117.

Squire, L. R., Haist, F., \& Shimamura, A. P. (1989). The neurology of memory: Quantitative assessment of retrograde amnesia in two groups of amnesic patients. Journal of Neuroscience, 9, 828-839.

Squire, L. R., NAdel, L., \& Slater, P. (1981). Anterograde amnesia and memory for temporal order. Neuropsychologia, 19, 141-145.

Squire, L. R., \& Shimamura, A. P. (1986). Characterizing amnesic patients for neurobehavioral study. Behavioral Neuroscience, 100, 866-877.

Tulving, E. (1972). Episodic and semantic memory. In E. Tulving \& W. Donaldson (Eds.), Organization of memory (pp. 381-403). New York: Academic Press.

Tulving, E. (1983). Elements of episodic memory. Oxford: Clarendon Press.

Tulving, E. (1986). What kind of a hypothesis is the distinction between episodic and semantic memory? Journal of Experimental Psychology: Learning, Memory, \& Cognition, 12, 307-311.

(Manuscript received September 12, 1990; revision accepted for publication December 10, 1990.) 